Yayınlayan: Ankara Üniversitesi KASAUM

Adres: Kadın Sorunları Araştırma ve Uygulama Merkezi, Cebeci 06590 Ankara

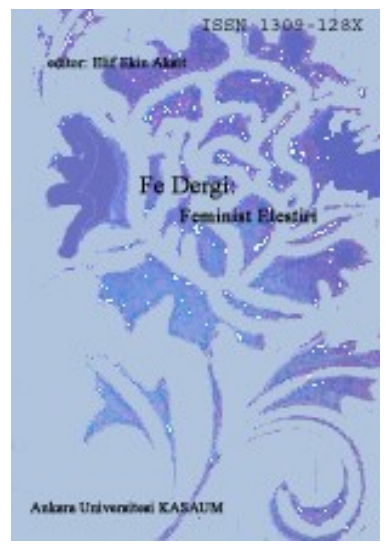

Fe Dergi: Feminist Eleştiri Cilt 3 Sayı 1

Erişim bilgileri, makale sunumu ve ayrıntılar için:

http://cins.ankara.edu.tr/

Doğurganlık kontrolünde rasyonelliğin sınırları:

Türkiye kürtaj ve gebeliği önleyici yöntem kullanımı

Alanur Çavlin Bozbeyoğlu

Çevrimiçi yayına başlama tarihi: 15 Haziran 2011

Bu makaleyi alıntılamak için: Alanur Çavlin Bozbeyoğlu, "Doğurganlık kontrolünde rasyonelliğin sınırları:

Türkiye kürtaj ve gebeliği önleyici yöntem kullanımı," Fe Dergi 3, no. 1 (2011), 24-37.

URL: http://cins.ankara.edu.tr/cavlin.html

$\mathrm{Bu}$ eser akademik faaliyetlerde ve referans verilerek kullanılabilir. Hiçbir şekilde izin alınmaksızın çoğaltılamaz. 


\title{
Doğurganlık kontrolünde rasyonelliğin sınırları: Türkiye kürtaj ve gebeliği önleyici yöntem kullanımı
} Alanur Çavlin Bozbeyoğlu

\begin{abstract}
Bu çalışmada gebeliği önleyici yöntem kullanma ve istenmeyen bir gebeliğe kürtaj ile son verme kararının verilme süreçlerini eleştirel bir gözle incelemek istiyorum. Nüfusbilim literatüründe yaygın olarak gördügümüz ekonomik indirgemeci yaklaşımın ötesine giderek, doğurganlık kontrolü yöntemleri (gebeliği önleyici yöntemler ve kürtaj) nedensellik içerisinde birbirleri ile ilişkili olarak ele alınmakta, konunun toplumsal ve kültürel yapı ve toplumsal çelişkilerle ilişkileri ön plana çıkarılmaktadır. Rasyonel doğurganlık davranışı teorisini eleştirdiğim bu çalışmada bu teoriye alternatif olarak doğurganlık kontrolünü bütünlüklü bir bakış açısı ile ele alıyorum. Bu amaçla da doğurganlığın cinsellikle ilişkisini, toplumsal cinsiyet normlarının, güç ilişkilerinin ve aile ideolojisinin cinsellik ve doğurganlık üzerindeki etkilerini tartışacağım. Çalışmanın ampirik kısmında ise Türkiye Nüfus ve Sağlık Araştırması 2003 (TNSA 2003) verilerinin analizlerine yer vereceğim.
\end{abstract}

Anahtar kelimeler: Kürtaj, gebeliği önleyici yöntemler, nüfusbilim, rasyonel doğurganlık davranışı, toplumsal cinsiyet ilişkileri

\author{
Limitation of rationality in reproductive behaviour: abortion and contraception practices in \\ Turkey \\ In this study, I present a critical exploration of the decision-making processes behind contraception \\ and abortion practices in Turkey. Rather than adhering to the mainstream economic reductionist \\ approaches found in population studies literature, I intend to focus on the means of fertility control, \\ (i.e. contraception and abortion) and their causal relationships with each other. I will underline the \\ interconnectedness between contraception and abortion within social and cultural structures and detail \\ the characteristics of fertility control within the context of social conflict. While I criticize rational \\ reproductive theory, I use a holistic approach with regards to fertility control. To this end, I will \\ discuss the relationship between fertility and sexuality, including the remarkable effects of gender \\ norms, power dynamics and family ideology, on those two important facets of culture. The empirical \\ data for this study is based on the Demographic and Health Survey, Turkey, 2003. The information \\ gathered demonstrates the prevalence and patterns of both contraception and abortion practices.
}

Key words: Abortion, contraception, population studies, rational reproductive behaviour, gender dynamics

\section{Giriş}

Gebeliği önleyici yöntemler ve kürtaj (istemli düşük) insanlık tarihi boyunca üremeyi düzenlemede yerlerini korumuş iki temel araçtır. Yöntem kullanma ve istenmeyen bir gebeliğe kürtaj ile son verme kararının nasıl alındığı, her iki yolun doğurganlığın sınırlandırılmasında nasıl rol oynadığı ve hangi bireysel ya da toplumsal faktörlerin bu kararlar üzerinde etkili olduğu bu çalışmanın temel ilgi alanlarıdır. Öncelikle doğurganlık ile iktisadi rasyonelite arasındaki ilişkiye eleştirel bir gözle bakacağım. Bu amaçla demografik geçiş modelini, iktisadi kalkınma ve nüfus meselesi üzerine tartışmaları, Türkiye'de doğurganlık davranışını çevreleyen toplumsal değerleri, cinsellik ve doğurganlık ilişkisi ile bireylerin doğurganlık üzerindeki kontrolünün koşullarını ve sınırlarını tartışmaya açacağım. Yine bu kısımda yöntem kullanımı ve kürtajın doğurganlık kontrolündeki yeri ile toplumsal, sınıfsal ve kültürel farklılıkların doğurganlık kontrolü ile olan ilgisine değineceğim. Takibeden bölümde, ulus devlet sürecinin başından itibaren doğurganlığı teşvik etmeye ve sınırlamaya yönelik devlet politikalarını farklı dönemler halinde ele alacağım. Bu çerçevede gebeliği önleyici yöntem kullanımı ve kürtaja ilişkin yasal düzenlemeleri içeren nüfus kanunlarına özel olarak yer vereceğim. Makalenin son bölümünde ise Türkiye Nüfus ve Sağlık Araştırması 2003 (TNSA 2003) verilerine dayanarak Türkiye'de gebeliği önleyici yöntem kullanımı ve kürtajla ilgili yaptığım analizleri sunacağım. Bu bulgular 
1şı̆̆ında doğurganlık davranışı ve kontrolünü etkileyen faktörleri ortaya koyarken farklı iktisadi rasyonellerin ve iktisadi olmayan rasyonellerin doğurganlıkla ilgisini göstermeye çalışacağım.

On dokuzuncu yüzyılda nüfus artışına ilişkin iktisatçılar arasındaki tartışma başlamış olsa da yirminci yüzyılın ortalarına kadar yüksek doğurganlık ve nüfus artışı gücün simgesi olarak kabul edilmiş, bu döneme kadar istenmeyen gebelikler kadınların bireysel sorunu olarak değerlendirilmiştir. Yine bu döneme kadar doğurganlık kontrolü yollarının sistemli üretimi ve dağıtımından söz edemeyiz. Ancak doğurganlığı önleyici yöntemler bölgesel olarak çeşitlilik göstererek 'kadınlara mahsus bir bilgi' olarak varolmuş ve kuşaktan kuşağa aktarılmıştır. ${ }^{1}$ Türkiye'de yaygın olmasa da hâlâ kullanımına rastladığımız cinsel ilişki öncesi vajinaya kibrit çöpü, sabun ve aspirin gibi cisimlerin yerleştirilmesi, cinsel ilişki sonrası yıkama-vajinal duş, gebe kalmamak ya da düşük başlatmak için bitki tohum ve kökleriyle hazırlanan karışımların içilmesi, düşük başlatmak için ağrı kesici ve aspirin başta olmak üzere çeşitli ilaçların içilmesi, yüksekten atlanılması, şiş gibi sivri cisimler kullanılarak kanama başlatılması bu dönemdeki folklorik yöntemlere ${ }^{2}$ örnek olabilir. Geleneksel yöntemler ya da tıbbi olmayan yöntemler olarak adlandırılan geri çekme (coitus interruptus) ve takvim yöntemleri (gebe kalma olasılığının fazla olduğu günlerde cinsel ilişkiden kaçınma) ise dünya nüfusunun önemli bir kesiminde gözlenebilir doğurganlık düşüşüne neden olan ilk yöntemleridir. Bu yöntemlerin doğru şekilde kullanımı ancak üreme fizyolojisinin ve adet döngüsünün tam olarak kavranması ile mümkün olabilir. Geri çekme yöntemi halen Türkiye'de kullanılan en yaygın gebeliği önleyici yöntemdir (yüzde yirmi altı), takvim yöntemi ise kadınların çok küçük bir bölümü (yüzde birden az) tarafından kullanılmaktadır. ${ }^{3}$ Üstelik gebe kalma olasılığının fazla olduğu dönem, kadınların dörtte üçü arasında ya bilinmemekte ya da yanlış bilinmektedir. ${ }^{4}$

Gebeliği önleyici yöntem kullanımı ve kürtaj konusunda nüfusbilim literatüründe genellikle karşılaştığımız; yöntem arzının (serbest piyasasının olgunlaşmış olması ve yasal düzenlemelerin oluşturulmuş olması) fazlasıyla öne çıkarıldığı, buna karşılık yöntem kullanımı ve kürtaja ilişkin talebin dinamiklerinin ikinci plana itildiği geleneksel bir yaklaşımdır. ${ }^{5}$ Talebi çok derin bir incelemeye tabii tutmaksızın verili kabul eden bu yaklaşımda, tek ve değişmez rasyonel doğurganlık davranışının var olduğunun kabulü önemli bir yer tutar. ${ }^{6}$ Sosyal bilimlerde rasyonellik kavramı iktisat teorisinden türetilmiştir. Benzer şekilde rasyonel doğurganlık davranışı yaklaşımı bilimsel temelini rasyonel seçim teorisinden (rational choice theory) almaktadır. Bu teoriye göre bireyler (iktisadi) istekleri ve amaçları etkisiyle hareket eder ve tercihlerini yaparken kazanç ve kayıplarını hesaplarlar. ${ }^{7}$ Rasyonel seçim teorisi penceresinden bakıldığında, rasyonel aktör/birey doğurganlık davranışını kendi refahını arttırma doğrultusunda kullanan kişidir. Teoriye göre bireyin içinde bulunduğu koşullarda tek bir rasyonel davranış biçiminden söz edilebilir. Rasyonel doğurganlık davranışı yaklaşımında, doğurganlık davranışı üzerinde bireylerin tamamen bilinçli bir kontrolü/belirleyiciliği olduğu varsayılmaktadır. ${ }^{8}$ Doğurganlık düşüşünde, doğurganlık davranışının bilinçli tercihlerin sonucu olmasının önemi Coale ${ }^{9}$ tarafından vurgulanmış ve pek çok çalışmada atıf yapılmıştır. Ancak bu bilinçlilikten anlaşılan yeterince tartışılmamıştır.

Bu makalede yöntem kullanımı ve kürtaj kararını belirleyen dinamiklere eleştirel bir yaklaşım getirmeyi amaçlıyorum. Türkiye Nüfus ve Sağlık Araştırması 2003 (TNSA 2003) verilerini kullanarak yaptığım analizleri çalışmanın hipotezlerinin ampirik veriler 1şığında tartışılması için kullanıyorum. Çalışmada gebeliği önleyici yöntem kullanımıyla kürtaj arasındaki ilişkiyi, doğurganlık davranışı üzerindeki kontrol vurgusuyla, üreme davranışını bir bütünlük içinde ele alarak değerlendirdim. Bu nedenle kürtaj ve yöntem kullanımını birbirinin yerine geçecek araçlar olarak değil doğurganlık kontrolünde farklı yerlere sahip araçlar olarak ele aldım.

TNSA 2003, Türkiye'de 1963 yılında başlayan ve beş y1lda bir düzenli olarak tekrar edilen nüfus araştırmalarının dokuzuncusu olup, örneklem tasarımı Türkiye genelinde, kır ve kent ayrımında, beş coğrafi bölge ve on iki alt bölge düzeyinde nüfus ve sağlı göstergelerini tahmin etmeye uygun olarak tasarlanmıştır. Ayrıca bu araştırma dizisi görüşme yapılan kadınların, eşlerinin ve ebeveynlerinin anadillerini öğrenmeye yönelik sorular içerdiğinden Türkiye'de etnik grupların büyüklüğünü, dağılımını ve nüfus ve sağlık göstergelerinin etnik gruplar düzeyinde farklılığını temsili olarak yansıtabilen tek araştırmadır. Araştırma bulgularım arasında yöntem kullanımı ve kürtajın yaygınlığına ilişkin betimsel göstergeler, yöntem kullanımı ve kürtaj yaptırma eğilimini etkileyen sosyal ve kültürel faktörler (lojistik regresyon yöntemi ile elde edilmiş), yöntem kullanımı ve kürtaj arasındaki ilişki ile diğer faktörlerin ilişkisini incelen (nedensellik ilişkisi yöntemi ile) modellere yer verdim. Ayrıca doğurganlık davranışı üzerine daha önce yapmış olduğum niteliksel araştırmanın analizlerine dayanarak kadınların yöntem ve kürtaj algısı ile davranışlarını belirleyen koşullara ilişkin bulgularıma yer verdim. 


\section{Doğurganlık ve iktisadi rasyonelite}

Demografik süreçler ve göstergelerin değişimini anlamlandırma ve öngörmede en yaygın kullanıma sahip yaklaşım olan demografik geçiş modeli, doğurganlık ve ölümlülük düzeylerindeki değişimi dört ana döneme ayırmaktadır: doğum ve ölüm oranlarının yüksek ve dengede olduğu ilk dönem, doğum oranlarının yüksek olmasına karşın ölüm oranlarının azaldığı ve nüfusun hızla arttığı ikinci dönem, hem doğum hem ölüm oranlarının hem de bunlara bağlı olarak nüfus artış hızının azaldığı üçüncü dönem ve doğurganlık düzeyinin nüfusun yenilenme düzeyinin altına düştüğü, ölüm düzeyinin minimum doğal sınırlara yaklaştığı ve nüfus büyüklüğünün sabit hale geldiği dördüncü dönem. ${ }^{10}$ Thompson, ${ }^{11}$ Davis ${ }^{12}$ ve Notestein ${ }^{13}$ tarafından biçimlendirilen klasik demografik geçiş modeli de Avrupa'da çocuk sahibi olma isteğindeki düşüşü makro iktisat temelinde açıklar. Model, dönemler arasındaki geçişi temel olarak sanayi öncesi iktisadi ve toplumsal ilişkilerden sanayileşmiş iktisadi ve toplumsal ilişkilere geçiş ile ilişkilendirmektedir. Doğurganlık davranışını biçimlendirdiği ya da biçimlendirmesi gerektiği ön görülen rasyonel seçim teorisi, demografik geçiş modelinin iktisadi kalkınmanın doğurganlık düzeyinde azalma ile sonuçlanacağı yaklaşımı ile uyumlu ve ilişkilidir. Ancak demografik geçiş modeli iktisadi indirgemeci bakış açısı ve batı Avrupa ülkelerinin nüfuslarının deneyimlerini evrensel deneyimler gibi değerlendirmesi nedeni ile önemli eleştiriler almıştır. Farklı coğrafyalardaki deneyimler bazı ülkelerde doğurganlık düşüşünün iktisadi kalkınma gerçekleşmeden yaşandığını ya da iktisadi kalkınmanın doğurganlıkta önemli değişimlere neden olmadığını göstermiştir. ${ }^{14} \mathrm{Bu}$ alandaki teorik çalışmalarda Coale'ın ${ }^{15}$ ortaya attığı doğurganlık düşüşünün üç temel koşulu sıklıkla kullanılmaktadır. ${ }^{16} \mathrm{Bu}$ koşullar sirasıyla (1) doğurganlığın bilinçli bir tercihin sonucu olması, (2) gebeliği önleyici etkin yöntemlerin ulaşılabilir olması ve (3) doğurganlığın düşüşünün bir avantaj olarak algılanmasıdır. Ancak literatürde iktisadi nedensellik kurmaya elverişli olan son koşul çok fazla ön plana çıkarılırken, bilinçli tercihin öneminin altını çizen ilk koşul gereken ilgiyi çekememiştir.

Güncel demografi yazınındaki bazı çalışmalar, nüfusla ilgili süreçlerin daha bütünlüklü olarak ve toplumsal ve kültürel bileşenler dikkate alınarak ele alınması gerekliliğini vurgulamaktadır. ${ }^{17}$ Benzer şekilde iktisat temelli olan rasyonel seçim teorisi kolektif insan davranışlarına uyarlanmadaki ve sosyal normları açıklamadaki zayıflığı nedeni ile de eleştirilmektedir. ${ }^{18}$ Doğurganlık davranışının dinamikleri oldukça karmaşık olup, bireylerin üreme davranışları ile ilişkili olarak daima iktisadi açıdan rasyonel kararlar almalarını mümkün değildir. Ayrıca doğurganlık tercihi gibi karmaşık bir süreç için rasyonelliğin tek bir yolundan bahsetmek de mümkün değildir. Doğurganlık kararı katı rasyonel bir süreç olsa idi çocuk sahibi olmak istemeyen tüm bireyler/çiftler gebeliği önleyi yöntem kullanır ya da istenmeyen tüm gebelikler kürtajla son bulurdu. Benzer şekilde Kertzer ve Fricke ${ }^{19}$ de doğurganlık davranışının dinamiklerinin açıklanması sırasında bireylerin rasyonel tercihlerine yapılan aşırı vurguyu eleştirmiş, kültürel özelliklerinin etkisinin göz ardı edilmesinden yakınmıştır. Geçmişte olduğu gibi günümüzde de doğurganlık davranışı yalnızca bireyler/çiftler tarafından değil gelenekler, normlar, değer sistemleri, toplumsal ve sınıfsal ilişkiler ile sivil ve dini yasalar tarafından belirlenmektedir. Söz konusu gelenekler, ilişkiler, değerler ve yasalar bireylerin içinde oldukları reel durumu ve karar aldıkları koşulları belirlediğinden bir arada devreye girerek gerçek ve karmaşık rasyoneli oluştururlar. Bu karmaşık yapının sonucunda ulaşılan karmaşı rasyonel, klasik iktisadi rasyonele aykırı şekilde ortalamadan daha fazla çocuk sahibi olmayı ya da çocuksuz bir yetişkin olmayı gerektirebilir. Demografi bir yandan toplumun dağılımını ve ortalamasını yansıtan çok kıymetli veriler üretirken öte yandan gerçek insanların gerçek deneyimlerinin ortalama içerisinde kaybedilmesi riskini taşır. Bu nedenle demografik göstergelerin analizi için çok yönlü eleştirel yaklaşımlar gereklidir.

Türkiye'de gebelik neredeyse tamamen heteroseksüel evlilik ${ }^{20}$ ilişkilerinin içerisinde gerçekleşir. TNSA 2008 sonuçlarına göre otuzlu yaşların ortalarındaki kadınların yüzde doksan altısı, doğurganlık çağının sonunki kadınların yüzde 99.9'u evlenmiş olup yüzde doksan sekizi en az bir canlı doğum yapmıştır. ${ }^{21}$ Evlilik ve anneliğin neredeyse evrensel olduğu Türkiye'de üreme davranışından bahsederken aslında bir yandan aile ideolojisinden ve kadınla erkek arasındaki cinselliğin dinamiklerinden bahsediyoruz. Foucault ${ }^{22}$ üremenin cinselliği yuttuğunu, üreme amacı dışındaki cinselliğin kolayca göz ardı edilebildiğini hatta ayıp, günah ve suç arasına kıstırıldığını anlatır. Demografi yazınında cinsellik üreme içerisinde de göz ardı edilmektedir. Yalnızca cinselliğin doğasının dikkate alınması bile doğurganlık davranışında beklenen rasyonellik konusunda şüpheli olmak için yeterlidir. Doğurganlık üzerindeki kontrolden bahsedilirken cinselliğin dürtüsel doğasının yanında toplumsal cinsiyet ilişkilerinin kadın ve erkek arasındaki cinselliğe yansıması dikkate alınmalıdır. Bu çalışmada kadının doğurganlığı üzerinde tam olarak kontrolü olduğunu varsayan yaklaşımları, özellikle toplumsal cinsiyet 
ilişkilerinin aile yapısını, çiftler arasındaki ilişkileri, ebeveyn olmanın anlamını ve cinselliğin kendisini biçimlendiren gücü nedeni ile eleştiriyorum. Türkiye'deki toplumsal normlar kadın cinselliğini yalnızca evlilik içerisinde kabul etmektedir. Evlilik anına kadar cinselliği yok hatta yasak olarak kabul edilen kadınlara, evlilik hayatının başlaması ile zorunlu bir cinsel hayat ve doğurganlıkla ilgili sorumluluklar yüklenmektedir. ${ }^{23} \mathrm{Kad}_{1 n} ı n$ doğurganlığı ile ilgili seçimlerini gerçekleştirebilmesi için her şeyden önce kadın ve erkek bedenini tanıması, üreme fizyolojisini bilmesi, cinsel ilişkilerini istediği zaman ve istediği şekilde yaşayabileceği koşulların oluşması gerekir. Kadına evli olmadığı için cinselliği yasakmak ya da evlilikle birlikte reddedilmez şekilde cinselliğe zorlamak, üstelik bu koşullarda kendisinin ve ailesinin iktisadi rasyoneli ile uyumlu doğurganlık davraşı geliştirmesi beklemek, kadının kendi bedeni üzerindeki söz hakkını ortadan kaldırarak sorumluluklarla donatan yaklaşımın bir ürünüdür. ${ }^{24}$ Rasyonel seçim teorisinin demografik süreçlere uyarlanmasındaki bir başka sıkıntı ise, Batı Avrupa ülkelerinde yaşanmış olan süreçlerin rasyonel bir model olarak kabul edilerek, dünyanın diğer coğrafyalarında tekrar edilmesinin beklenmesidir. Bu beklenti çok güçlü şekilde demografik değişimleri iktisadi kalkınma penceresinden açıklayan ve yüksek doğurganlık düzeyini iktisadi olarak geri kalmışlığın hem nedeni hem de sonucu olarak gören yaklaşımdan beslenmektedir. Ancak küresel doğu ve güney ülkelerinin çok farklı demografik süreçler geçirmeleri ve kaçınılmaz olduğu varsayılan demografik bütünleşmenin (benzeşmenin) gerçekleşmemesi indirgemeci bir yaklaşımla pek çok toplumun deneyimini irrasyonel olarak adlandırmaya neden olur. Başka bir deyişle iktisadi kalkınmanın rasyonel toplumun ve bu toplumun rasyonel bireylerinin vazgeçilmez hedefi olarak resmedilen dünya görüşünde yüksek doğurganlık irrasyonel bir sapmadır. Oysa modernite öncesinde olduğu gibi modern toplumlarda da doğurganlık davranışı yalnızca bireyin ve toplumun iktisadi hedefleriyle değil toplumsal, sınıfsal, kültürel ve duygusal gereklilikler ve çelişkiler içerisinde ortaya çıkar. Gebeliği önleyici yöntem kullanımı ve kürtaj konusunda yasal düzenlemeler bölgesel ya da ulusal sınırlar içerisinde farklılık göstermese de toplumsal, sınıfsal ve kültürel farklılıkların bu yolların kullanılma düzeyi üzerinde yarattığı farklılıklar kolayca gözlemlenebilmektedir. Bu nedenle yöntem kullanımı ve kürtaj üzerine yapılan tartışmaların farklılıklarla ilişkilendirilerek ilerlemesi gereklidir. Ayrıca yöntem kullanımı ve kürtaja yönelik yaklaşımlardaki farklılık da göz önünde tutulmalıdır. Agadjanian'ın ${ }^{25}$ deyişiyle “yöntem kullanımı ve kürtaj davranışının algısındaki farklılık toplumsal ve kültürel olarak inşa edilmiştir”. Bu durum her iki yolun yasal ve ulaşılabilir olması durumunda dahi gebelik öncesi ve sonrasında alınan kararlarda farklı dinamikler yer alır.

\section{Yöntem kullanımı ve kürtajla ilgili yasal çerçeve}

Dünya genelinde gebeliği önleyici yöntemlerin kullanımı ve kürtaj yasalara bağlı olarak düzenlenmektedir. Dini ve toplumsal değerlerden de etkilenerek olgunlaşan yasal düzenlemeler doğurganlık konusunda kadın bedeni üzerindeki ailevi, dini ve toplumsal tahakkümün resmi belgeleridir. Bu düzenlemeler bir yandan hizmetlerin ve ürünlerin kalitesine ilişkin standartlar oluştururken pek çok açıdan kadın bedeninde oluşacak ya da oluşmuş gebeliğe ilişkin kontrolü kadının elinden almaktadır. ${ }^{26}$ Türkiye Cumhuriyeti'nin kuruluşundan 1950'lerin sonuna kadar belirgin olarak pronatalist (nüfusu arttırmaya yönelik) bir nüfus politikası izlenmiştir. Bu politika nedeniyle gebeliği önleyici yöntemlerin üretilmesini, ithalini, uygulamasını ve gebeliğin isteyerek düşükle sonlandırılmasını suç olarak kabul eden yasal düzenlemelere ${ }^{27}$ gidilmiştir. Ayrıca bu politika, çok sayıda çocuk sahibi olmayı doğrudan ya da dolaylı olarak özendiren ücretsiz doğumevlerinin kurulması, ${ }^{28}$ yasal evlenme yaşının erkekler için on sekizden on yediye kadınlar için on yediden on beşe indirilmesi ${ }^{29}$ ve altı çocuk sahibi olan kadınlara madalya verilmesi gibi uygulamalarla desteklenmiştir.

Cumhuriyetin ilk yıllarında kadınlara yönelik politikalar incelendiğinde, toplumsal cinsiyete dayalı normların ve aile ideolojisinin yeni siyasi ve toplumsal düzen içerisindeki inşası dikkat çekicidir. Bu dönem politikaları devletin birbiriyle çelişkili gibi görünen uygulamalarını içerir. Bir yandan kadının eğitim hayatına ve ev dışı emek piyasasına girmesinin "batılı modern Türkiye toplumu” için önemi ve gereği vurgulanırken öte yandan evliliğin, anneliğin ve yüksek doğurganlığın güçlü Türkiye'nin olmazsa olmaz bir şartı olarak desteklendiğini görüyoruz. ${ }^{30}$ Uygulanan pronatalist politikalar yirminci yüzyılın ilk yarısına özgün dünya koşullarında özellikle de uzun yıllar süren savaşlar ve göçlerle büyük oranda genç nüfus kaybetmiş bir ülke için gerekliliği açık politikalardır. Onuncu Yıl Marşı'nın “on yılda on beş milyon genç yarattık her yaştan” dizesi de ilk on yılın önceliklerini göstermesi açısından son derece önemlidir. Kadınlara yönelik politikalarda bu öncelikli misyon ile çelişen politik söyleme bir başka açıdan bakarsak, kadının eğitim hayatına ve ev dışı emek piyasasına girmesine yönelik desteğin kadının evlilik ve aile içi geleneksel rolleri ile çelişmeyecek şekilde 
biçimlendirildiğini görürüz. Ayrıca farklı sosyal ve sınıfsal tabakalardan kadınlara pek çok rejim gibi Cumhuriyet Türkiyesi de farklı roller öngörmektedir. Batılı modern Türkiye'nin sembolü olacak kadınlarla, “on beş milyon genç" yaratırken altın madalya alacak kadınlar farklı tabakalardan gelmekteydi.

1950'lerde yüksek doğurganlık ve nüfus artış hızı çevresinde başlayan tartışmalar antinatalist nüfus politikasına gerekçe oluşturmuştur. 1965 yılında başlayan planlı dönemle birlikte yeni nüfus yasal çerçevesi oluşturmuş ve bu tarihte hazırlanan 557 sayılı Nüfus Planlaması Hakkında Kanun ile gebeliği önleyici yöntemlerin satışı, ithal ve uygulanması yasal hale gelmiştir. Kürtaj ve sterilizasyon yöntemleri ise hala yasa dışıdır. 1983 yılında kabul edilen 2827 sayılı Nüfus Planlaması Hakkında Kanun ile ise onuncu haftaya kadar gebeliklerin isteğe bağlı olarak sonlandırılması ve kadın ve erkeklerin tüplerinin bağlanması yasallaşmıştır. Aynı yasa evli kadınların gebeliği sonlandırmak istemesi durumunda eşlerinin yazılı izni, kadının on sekiz yaşın altında olması durumunda ise ebeveyninin iznini şart koşmuştur. ${ }^{31}$ Gebeliği önleyici yöntem ve kürtaj karşıtı yasal düzenlemeler "resmi" yöntem arzını belirlemiş olsa da, bu dönemde tedrici şekilde artan talebi değiştirmemiştir. Osmanlı'nın son ve Cumhuriyet'in ilk yıllarındaki doğurganlık ve yöntem kullanımı ile ilgili çalışmalar başta İstanbul ve İzmir olmak üzere büyük kent merkezlerinde yöntem kullanımının (çoğunlukla geri çekme) yaygın olduğu ve istenmeyen gebeliklere kürtaj ile son verilmesine rastlandığını göstermektedir. ${ }^{32}$ Türkiye'de doğurganlık konusunda temsili araştırmaların yapılmaya başladığı 1963 yılından sonraki veriler kürtajın yasal olmadığı dönemde neredeyse sabit bir yaygınlığının olduğunu göstermektedir. Yasa değişiklikleri ise Batı Avrupa ve Kuzey Amerika ülkelerindeki deneyimlerden farklı olarak tabandan/kadınlardan gelen baskı ve istekle değil, her ikisi de askeri cunta dönemlerinin ardından tepeden gerçekleşmiştir. Bu haliyle kadın özgürlük hareketinin bir parçası olmaktan çok devletin üreme üzerindeki kontrolünün bir parçası olarak biçimlenmiştir. ${ }^{33}$ Feminist yazının altını çizdiği şekilde ne kürtajın yasal olması ne de yöntemlerin ulaşılabilir olması kadının doğurganlık üzerindeki kontrolünü tek başına garanti altına alamaz. ${ }^{34}$ Yine de özellikle kürtaj konusundaki yasanın ehil olmayan kişiler ve uygun olmayan mekanlarda yapılan kürtajın önüne geçmek yoluyla kadın sağlığı açısından önemli bir tehdidi ortadan kaldırdığını belirtmek isterim. Kürtajın yasal olmadığı ülkelerdeki deneyimler kürtajın sağlıksız yerlerde ve koşullarda yapılmaya devam ettiğini göstermektedir. ${ }^{35}$

Kadın bedeni üzerinde doğurganlığa ilişkin tahakküm doğurganlığı önlemekle sınırlı olmayıp, doğurganlığı teşvik etmek ya da daha keskin bir deyişle kadının her koşulda zorunlu annelik rolü için yönlendirme işlevi görür. Bu tutum pronatalist politikalar döneminde olduğu gibi günümüzde de örneğin kısırlık tedavilerinin arka planında görülebilir. ${ }^{36}$

\section{Araştırma bulguları}

Türkiye'de beş yıllık aralıklarla yapılan nüfus ve sağlık araştırmaları doğurganlık sağlığı konusunda temel göstergeleri ulusal ve bölgesel düzeyde ve farklı toplumsal tabakalar için tahmin etmemize olanak sağlamaktadır. Bu çalışmanın temel veri kaynağı olan Türkiye Nüfus ve Sağlık Araştırması 2003'te ülke genelinde doğurganlık çağındaki (15-49 yaşları arasındaki) evlenmiş kadınlara gebeliği önleyici yöntemler ve kürtaj konusunda bilgilerini, tutumlarını ve davranışlarını anlamamıza yarayacak sorular sorulmuştur.

Türkiye'de kadınların tamamına yakını gebeliği önleyici yöntemleri duymuş ve kullanmayı denemiştir. Araştırma sonuçlarına göre evlenmiş kadınların yüzde doksanı en az bir kez gebeliği önleyici yöntem kullanmıştır. Araştırma esnasında, evli kadınların yüzde yetmiş biri herhangi bir yöntem kullanmaktadır. En yaygın yöntem geri çekme olup, kadınların yüzde yirmi altısı eşlerinin geri çekme yöntemini kullandığı söylemiştir. Bu yöntemi yüzde yirmilik kullanım payı ile RİA ve yüzde on birlik kullanım payı ile kondom izlemektedir. Gebeliğe cinsellikten soyutlamadan baktığımızda, tüm yöntemlerin çiftlerin cinsel isteği, uyumu ve hazzı üzerinde etkili olduğunu ve bu durumun da yöntem tercihini ve yöntemlerin kullanım başarısını etkilediğini görürüz. Yöntemlerin sıklıkla dile getirilen etkilerini sıralayacak olursak kadınlar geri çekme yönteminin gebelik riski kaygısını arttırmasından şikayet ederken, hem erkekler hem de kadınlar kondomu cinsel hazzı azalttığı gerekçesi ile daha az tercih etmektedir. Kadınların bir bölümü doğum kontrol hapı ve iğnesini cinsel isteksizlik ve orgazm zorluğuna neden olduğu için kullanmak istenmezken, bir bölümü ise RİA'nın cinsel birleşme sırasında ağrıya neden olduğundan yakınırlar. ${ }^{37}$ Araştırma sırasında kullanılan yöntemlerden yola çıkarak, çiftlerin üçte birinden fazlasının (yöntem kullanan çiftlerin yarısının) cinsel ilişki sırasında erkeklerin kullandığı yöntemler yoluyla gebelikten korunduklarını söyleyebiliriz. Bu çıkarım okuduğunuz yazının ilgi alanına ilişkin olarak iki açıdan önemlidir. Çiftlerin kullanacakları yöntem için birlikte karar vermiş olduklarını kabul etsek dahi ilişki sırasında yöntemin kullanılmasına dair rasyonelite cinsel arzudan ve hazdan etkilenir. Geri 
çekme ve kondomu kullanacak kişi erkek olduğundan özellikle erkeğin cinsel hazzı ile yöntem kullanma rasyoneli arasında kurduğu denge önemli hale gelir. Literatürde yöntem başarısızlığı ve kullanım hatalarına ilişkin çok sayıda çalışma vardır. Türkiye'de yaygın olan yöntemlerden geri çekmeyi kullananların yüzde on yedisinin yöntem başarısızlığı yaşadığı (kullanım sırasında gebe kaldığı) bu oranın kondom kullananlar arasında yüzde sekiz ve RİA kullananlar arasında yüzde ikiden az olduğunu görmekteyiz. ${ }^{38}$ Geleneksel yöntemlerin başarısızlık oranının daha yüksek oluşu nedeniyle istenmeyen gebeliklerle ve kürtajla ilgisi daha önceki çalışmalarda da ele alınmıştır. ${ }^{39}$ Ancak bu konuda dikkat çekmek istediğim nokta yöntem başarısızlığının nedenlerinin her yöntem için benzer şekilde değerlendirilmesinin eksikliğidir. RİA kullanımındaki başarısızlık, yöntemin kullanılmasına rağmen taşıdığı başarısızlık riskidir. Ancak geri çekme ve kondom kullanımı sırasındaki risk ayrıca genel olarak bu yöntemleri kullanan çiftlerin söz konusu cinsel birleşme sırasında yöntemi uygulamamalarından ya da hatalı uygulamalarından kaynaklanır. Bu hali ile daha çok kullanana ve kullanıma bağlı hatalardır. Bu durumda gebeliği cinsellikten ayrı olarak algılamak konuyu tamamen eksik kavramamıza neden olmaktadır. Ayrıca her iki yöntem için de son kertede karar verici olan erkektir. Diğer bir deyişle yöntemin uygulanıp uygulanmaması ve kullanım başarısı önemli ölçüde erkeğe bağlıdır. Bu durumda kadının doğurganlık üzerindeki kontrolünden ve gebelikle ilgili rasyonel kararından bahsetmek çok tartışmalıdır. Kadınlar geri çekme yöntemini anlatırken çok farklı ifadeler kullanırlar. Yaygın bir ifade "eşime güveniyorum" ifadesidir. ${ }^{40} \mathrm{Bu}$ ifade çiftler arasındaki doğurganlığa ilişkin sorumluluk ve kontrolü yansıtması açısından dikkate değerdir.

Dünya genelinde tüm gebeliklerin yarısı, doğumla sonuçlanan gebeliklerin ise dörtte biri istenmeyen gebeliklerdir. Demografik araştırmalar, gelişmiş ülkelerde istenmeyen gebeliklerin daha büyük bir kısmının kürtajla sonuçlandığını, gelişmekte olan ülkelerde ise istenmeyen gebeliklerin doğumla sonuçlanma olasılığının daha fazla olduğunu göstermektedir. ${ }^{41} \mathrm{Bu}$ sonuçları yorumlarken ülkelerin kendi içerisinde de önemli farklılaşmalar olduğunu hatırlamalıyız. Yaş, eğitim durumu, yerleşim yeri, anadil, etnisite ve refah düzeyi gibi temel ayrımlarda değerlendirmeler yapıldığında yöntem kullanımının daha yaygın olduğu toplumsal tabakalarda istenmeyen gebeliklerin kürtajla sonuçlandırılmasının da daha yaygın olduğu görülmektedir. Daha önce yapılmış çalışmalar gibi okumakta olduğunuz çalışmanın analizleri de "modern yöntem” kullanan kadınların istenmeyen gebelik durumunda kürtaj yaptırma eğilimlerinin daha fazla olduğunu göstermektedir. Oysa geleneksel yöntemlerin başarısızlık oranı, diğer bir deyişle kullanım sırasında gebe kalma riski, daha fazladır. Ancak kadınların gebelikle ilgili kararı alırken (gebeliği sürdürmek ya da devam etmek yönünde) içinde bulundukları koşulları daha titiz bir gözle değerlendirirsek birkaç önemli nokta gözümüze çarpar. İlki gebeliği ertelemek amacı ile yöntem kullanan kadınların bir daha gebe kalmayı hiç istemeyen kadınlara göre kürtaja daha az eğilimli olduğudur. Geleneksel yöntemlerin (Türkiye için esas olarak geri çekme yönteminin) ertele amacıyla daha yaygın kullanıldığı bilinmektedir. ${ }^{42}$ Bu durumda geri çekme kullanırken gebelik olması durumunda farklı bir rasyonel devreye girerek, kürtaj yerine istediğinden erken bir zamanda çocuk sahibi olmaya karar verimesi daha anlaşılır bir durumdur. Ayrıca “modern yöntemleri” kullanan kadınlar doğum kontrolü için sağlık hizmetlerine halihazırda başvurmuş olan kadınlardır. Dolayısıyla bu kadınların istenmeyen bir gebelik durumunda da benzer sağlık kurumlarına ulaşmaları daha kolay olabilir. Geri çekme yönteminin tercih edilme nedenlerinden biri yöntemin herhangi bir masrafının olmamasıdır. Türkiye'de her dört kürtajdan üçünün özel doktor muayenehanesinde para karşılığında yapıldığını göz önüne alırsak yöntem kullanımı için masrafsız bir yol seçen çiftlerin istenmeyen gebelik durumunda kürtaj masrafını karşılayamamış olabileceği iktisadi açıdan da rasyonel bir durumdur.

Türkiye'de ilk gebeliğin kürtajla sonuçlanmasının kısırlığa neden olacağına dair yaygın bir inanç vardır. $\mathrm{Bu}$ inanç ilk gebeliğe müdahalenin tıbbi farklılığından ziyade kadınların ilk gebeliğini tartışmasız şekilde doğumla sonuçlandırmaları gerektiğine dair toplumsal kabulden beslenmektedir. Kürtajın kadın sağlığı açısından riskler taşıdığı bir gerçektir. Ancak araştırmaların gösterdiği pek çok kadının herhangi bir fiziksel sağlık sorunu yaşamasa da uzun yıllar sürebilen psikolojik etkiler altında kaldığı, utanç, pişmanlık, suçluluk ve unutma isteği duyduğudur. Bu etkilerin biçimlenmesi, güçlenmesi ve yerleşmesi dini, vicdani ve toplumsal baskılarla oluşmaktadır. Kürtajın yasal olmadığı 1983 yılı öncesinde de kullanıldığını bildiğimiz Türkiye'de, bu kararın kolayca alındığını söylemek mümkün değildir. 2002 yılında yaptığımız niteliksel araştırmanın sonuçları, kürtajın gebeliği önleyici yöntem yerine kullanılmadığı, aksine "son çare” olarak görüldüğünü göstermiştir. ${ }^{43}$ Diğer bir deyişle, gebeliğin istenmeme nedeni (maddi olanakların çocuk bakmaya uygun olmaması, çocuk sahibi olmak istememesi gibi çok yaygın nedenler sıralanabilir), ile sağlık hizmetlerine erişebilirlik ve kürtaja ilişkin değer yargıları arasında ağır basan taraf gebeliğin ne şekilde sonuçlanacağını belirler. Böylesi bir durumda hanenin ya 
da kadının iktisadi çıkarı açısından bir fayda sağlamayacak olsa da eşi izin vermediği için kürtaj yaptırmayan bir kadının, inaçları gereği, kürtaja karşı olan bir çifti ya da yaşadığı yerde kürtaj yapılabilecek bir sağlık kuruluşu olmayan bir kadının kararının rasyonel olmadığını söyleyemeyiz.

Türkiye'de her dört kadından biri en az bir kez kürtaj yaptırmış olup, kürtaj yaptıran kadınların yüzde kırk ikisi istenmeyen gebelik durumunda birden çok defa kürtaja başvurmuştur. Araştırma tarihinden önceki üç yıllık dönemdeki gebelikler incelendiğinde her yüz gebeliğin on ikisinin kürtajla sonuçlanmış olduğu görülür. Gebeliği önleyici yöntem kullanımı ve kürtaj arasındaki ilişkiye baktığımızda, kürtajın yöntem kullanımına bir alternatif olarak kullanılmadığı kürtaj yaptıran kadınların tamamına yakınının (yüzde doksan dokuzunun) yöntem kullanan kadınlar olduğu üstelik yüzde doksan ikisinin "modern bir yöntem” kullanmış olduğunu görüyoruz. Kürtajların önemli kısmı gebeliklerin arası açmaktan ziyade doğurganlığa son vermek için yapılmaktadır. Başka bir deyişle istenmeyen bir gebelik durumunda bir daha hiç çocuk sahibi olmak istemeyen kadınların gebeliği kürtajla sonuçlandırması eğilimi daha sonra çocuk sahibi olmak isteyen kadınlara göre daha fazladır. ${ }^{44}$ Çok değişkenli lojistik analiz yöntemi ile kadınların sosyal ve demografik özelliklerini incelediğimizde çocuk sayısının, yöntem kullanmış olmanın, ekonomik refah seviyesinin ve etnik-kültürel özelliklerin kürtaj yaptırmış olma ile güçlü bir ilişkisi olduğunu görürüz. Kürtaj yaptırmış olup olmama ile araştırma tarihinde yöntem kullanıyor olup olmamanın ilişskisi test edildiğinde, yöntem kullanımı ile kürtaj yaptırma arasındaki paralel ilişki doğrulanır. Bu analizden çıkan sonuçlara göre yöntem kullanmış olmak kürtaj yaptırmış olmak için kürtaj yaptırmış olmak ise yöntem kullanıyor olmak için istatistiksel olarak anlamlı belirleyiciler olarak ortaya çıkmıştır. Analiz sonuçları yöntem kullanan kadınların kürtaj yapma eğiliminin yöntem kullanmayanlardan yaklaşık dört kat daha fazla olduğunu göstermiştir. Farklı ülkelerde yapılan çalışmalar da benzer bir ilişkiyi doğrular niteliktedir. ${ }^{45}$ Kürtaj yaptırmış olma eğilimi ekonomik refahla birlikte artarken, kendi ev işleri dışında çalışan kadınların istenmeyen bir gebelik durumunda kürtaj yapma eğilimi çalışmayan kadınlardan 1.27 kat daha fazladır. Etnik farklılıklar değerlendirildiğinde Kürt kadınların kürtaj yaptırmış olma eğiliminin Türk kadınlarının yarısı kadar olduğu görülür. Bu sonuçları çalışmamın temel ilgi alanları açısından yorumladığımda gebeliği önleyici yöntem kullanan kadınların diğer doğurganlık sağlı̆̆ hizmetlerine ulaşma kanallarının daha açık olduğunu, ekonomik refahla birlikte çocuğa yapılan yatırımın artmasının istenilen çocuk sayısını azaltığını, özel alandan ziyade bir kamusal alan meselesi olan kürtajın ev dışında çalışan kadınlar için daha ulaşılabilir olduğunu, sağlık hizmetlerinde yalnızca Türkçe'nin kullanılmasının Kürt kadınların bu hizmetleri tanıması, ulaşması ve hizmetlerin kalitesine güvenmesi açısından bir engel oluşturduğunu ve istenilen çocuk sayısının Kürt kadınları arasında Türk kadınlarından daha fazla olduğunu söyleyebiliriz. Doğurganlık davranışını çevreleyen faktörleri bu şekilde daha geniş olarak anlamlandırıldığımızda, tercihlerin arkasında yatabilecek farklı rasyoneller de görülmektedir.

Gebelik isteği, gebeliği önleyici yöntem kullanımı ve kürtaj arasındaki ilişkiyi etkileyen faktörleri bütüncül olarak incelemek üzere nedensellik ilișkisi modeli (causal model) oluşturulduğunda bu faktörlerin doğurganlık kontrolü üzerindeki dolaylı ve dolaysız etkilerini görmek mümkün olabilmektedir. Her ne kadar yöntem kullanımı ve kürtaj ortak bir nihai amaca hizmet ediyor ve doğurganlığı engelliyor olsa da yöntemlerin gebe kalmadan önce uygulanıyor olması kürtajın ise gebe kaldıktan sonra uygulanması hem bu iki yolun işlevini hem de bireysel ve toplumsal faktörlerin bu kararları alırken etkilerini farklılaştırmaktadır. Bu nedenle yöntem kullanımı ve kürtaj arasındaki ilişkiyi ve faktörlerin dolaylı ve dolaysız etkilerini incelemek son derece akıl açıcıdır. Çalışmada kullanılan modelde yer alan gebelikler araştırma öncesindeki yetmiş iki aylık dönemde gerçekleşen doğumla ya da kürtajla sonuçlanan tüm gebeliklerdir. Doğumla sonuçlanan gebelikler için, bu gebeliğin istenip istenmediği görüşme yapılan kadınlara sorulmuş, kürtajla sonuçlanan gebelikler ise istenmeyen gebelik olarak değerlendirilmiştir. Bu model ile yöntem kullanımı ve kürtaj ilişkisi bütünsel bir yaklaşımla ve etnik-kültürel farklılık vurgusuyla ele alınmıştır. Modelde nedensellik ilişkisi, önceki analiz aşamalarında önemli olduğu görülmüş olan "gebelik isteği”, "gebelik öncesi yöntem kullanımı”, "gebelik sonucu (kürtaj ya da canlı doğum)", "hayatta olan çocuk sayısı" ve "eğitim” değişkenleri ile oluşturuldu. Etnik-kültürel farklılık değişkeninin moderatör olarak yer aldığı modelde, bu farklılığın yöntem kullanımı ve kürtaj kararı üzerinde hem doğrudan hem de dolaylı etkisi olduğunu görürüz. Yöntem kullanımı gebelik isteği, hayatta olan çocuk sayısı ve eğitimi etkilemekte bu dolayımla kürtaj kararında da etkili olmaktadır.

Daha sonra aynı yapısal eşitlik modelinin geçerliliği üç etnik-kültürel grup için ayrı ayrı çoklu grup analizi metodu ile değerlendirildi. Çoklu grup analizi sonuçları Türkiye geneli için geçerli olan yapısal modelin Türkler için büyük oranda geçerli olduğunu ancak Kürtler için geçerli olmadığını göstermektedir. Bu sonuçlar yöntem kullanımı ve kürtaj arasındaki ilişkinin doğurganlık düzenlenmesinin bütünlüklü olarak ele alındığı bir 
bakışla incelenmesinin önemini ve bu ilişkinin etnik-kültürel gruplar için daha belirgin farklılar gösterebileceğini doğrulamıştır. Nüfusun tüm alt grupları için geçerli tek bir geçerli modelden söz etmek mümkün değildir.

Oluşturulan modellerde, gebeliği önleme ve gebeliğe son verme kararında etkin olduğunu düşündüğümüz eğitim, etnik farklılık, gebelik isteği gibi değişkenlerin birbirleri ile ilişkisinin ne kadar önemli olduğu ve bu ilişkileri göz ardı ettiğimiz durumlarda yaptığımız değerlendirmelerin indirgemeci değerlendirmeler olma riski taşıdıkları görülmektedir.

\section{Sonuç ve değerlendirme}

Doğurganlık davranışı, iktisadi kalkınma temelli kavrayış ve değerlendirmelerde bireylerin iktisadi faydalarını arttırma yolundaki rasyonel kararları ile biçimlenmesi beklenen bir davranıştır. Türkiye gibi çocuk sahipliğinin heteroseksüel aile içerisinde olmasının norm halinde olduğu ülkelerde söz konusu rasyonel ailenin rasyonel kararı anlamına gelir. Bu bakış doğurganlık tercihleri şeklinde ifade edilebilecek süreçleri aile planlamasına indirgerken, aile adına kadını sorumlu kılar. Yine bu yaklaşımın bir sonucu olarak Türkiye gibi evlilik öncesinde kadının cinselliğinin yok sayıldığı, toplumsal olarak yasaklandığı bir ülkede evlilikle beraber kadının ailesinin çıkarlarına en uygun şekilde doğurganlığını planlaması beklenir. Bakabileceği kadar çocuk sahibi olma kavramı bu yaklaşımın en yumuşak ifadesidir. Ancak bu beklentiye aykırı durumların pekâlâ akla uygun olmadığı, bilinçsizlik olduğu hatta daha suçlayıcı bir yaklaşımla sorumsuzluk olduğu şeklideki yorumlarla sıkça karşılaştığımız unutulmamalıdır. Bu yaklaşımla yoksulluğun daha yoğun olduğu sosyal tabakalardan kadınlar, kent yoksulları, kırsal alanlarda yaşayan kadınlar, okuryazar olmayan ya da daha az eğitimli kadınlar, Kürt kadınlar Türkiye ortalamasının üzerinde çocuk sahibi oldukları için suçlanmaktadırlar. Türkiye genelinde doğurganlık düzeyinin bir tehdit olarak görülmeye başladığı 1950lerin son döneminde olduğu gibi, kadın başına düşen ortalama çocuk sayısının 2.1 olduğu günümüzde de belirli toplumsal tabakalardan kadınlar (ve erkekler) çocuk sahibi olmaya uygun görülmemektedir. ${ }^{46}$ Aslında bu bakış açısı yoksulluğun yaygınlaşmasının nedeni yoksul kesimlerin daha fazla çocuk sahibi olmalarına bağlayarak İngiltere'deki Yoksulluk Yasa'sını eleştiren ve yoksullara yapılan devlet yardımına karşı çıkan Malthus'un ${ }^{47}$ yaklaşımının bir uzantısıdır.

Doğurganlık sürecini etkileyen faktörlerin karmaşıklığı, bu süreci kavramada iktisadi rasyonelin ötesinde bir bakış açısını gerekli kılar. Bu çalışmada aile ideolojisi, dini ve toplumsal değerlerin etkisi, toplumsal cinsiyet ilişkileri ve doğurganlığın cinsellikle ilişkisi ön plana çıkarılarak doğurganlık davranışındaki rasyonelliğin sınırlarını tartışmaya açtım. Bu tartışma içinde gebeliği önleyici yöntemlerin kullanımı ve istenmeyen gebeliklere kürtaj ile son verme kararını etkileyen faktörlere yoğunlaştım.

Üreme isteği tek başına üreme davranışın belirleyicisi değildir. Bu nedenle de sıklıkla gebelik isteği olmadığı halde yöntem kullanılmadığı durumlarla ve gebelik istenmediği halde doğum yapılması ile karşılaşırız. Üreme isteğinin rasyonelliğini bir kenara bırakırsak, bu isteği hayata geçirebilen kadınların kendi bedenleri üzerinde söz sahibi olmalarını görece kolaylaştıran bazı sosyal ve sınıfsal koşullardan geldiklerini görebiliriz. Bunun sonucu olarak hem gebelik öncesi hem de sonrasında benzer gruplardaki kadınların (yüksek gelir gruplarından, eğitimli, kendi ev işleri ve tarım sektörü dışında çalışan, kentli ve Türk kadınların) yöntem kullanma ve kürtaj yolu ile doğurganlıklarına daha fazla müdahale edebildiğini görmekteyiz.

Türkiye'de yöntem kullanımı evli çiftler arasında yüzde yetmiş düzeyindedir. Her yüz gebeliğin yaklaşık on ikisi kürtajla sonuçlanmaktadır. Yöntem kullanımı-istenmeyen gebelik-kürtaj arasındaki ilişki değerlendirilirken cinselliğin nasıl yaşandığına, cinsel hazzın, erkeğin kadın üzerindeki cinsel baskısının, yöntem tercihi ve kullanımında karar verenin kim olduğunun, aile kurumu içerisinde kadından beklenen çocuk doğurma ve yetiştirme sorumluluğunun rasyonel doğurganlık davranışı yaklaşımı ile açıklanması mümkün değildir.

Doğurganlığın cinsellikten koparılarak kavranmaya çalışıldığı yaklaşımda toplumsal cinsiyet ilişkilerini, güç ilişkilerini, şiddeti ve aile ideolojisini gözden kaçırılmaya mahkumdur. Oysa Foucault'un ${ }^{48}$ cinselliği güç ilişkileri içerisinde hatta güç ilişskilerinin merkezinde konumlandıran yaklaşımı, Marx ${ }^{49}$ ve Engels'in ${ }^{50}$ kapitalizmin ve kapitalizmin belkemiğini oluşturan özel mülkiyetin aile ideolojisinden beslenişini kavramsallaştıran yaklaşımları, feminizmin kadın bedeni üzerindeki tahakkümün bir yandan annelik ve doğurganlıkla beslenen bir yandan kadın cinselliğini nesneleştiren ataerkil ideolojiye karşı eleştirileri doğurganlık davranışını salt iktisadi rasyonelle ilişkilendirmenin toplumsal olanı kavramamıza yetmeyeceğini açıkça göstermektedir.

Rasyonel seçim teorisinin doğurganlığa uyarlanmış hali gebeliğe ilişkin kararların iktisadi iyilik hali ön planda tutularak alınması gereğini savunur. Ancak doğurganlık davranışını belirleyen tek rasyonel iktisadi 
rasyonel değildir. İnançlı birinin inancı gereği kürtaj yaptırmamak istemesini, cinsel arzunun ve hazzın gebelik kaygısının önüne geçmesini, geleneksel iş bölümünde emeğinin (temel olarak ev içi işlere harcadığı emeğin) önemli kısmı biriktirilemeyen ve gündelik olarak tükenen kadının doğurduğu ve büyüttüğü çocuklarda kendi emeğini görmesinin, güvenebileceği ve ulaşabileceği doğurganlık sağlığı hizmetleri kısıtlı olan kadınların gebe kalmak istemedikleri halde yöntem kullanmamalarının ya da istenmeyen bir gebeliği doğumla sonuçlandırmalarının iktisadi rasyonelden bağımsız rasyonel yanları vardır. Çocuk sahibi olmayı rasyonel kılan yalnızca hanede kişi başı düşen gelirin bir sınırın üzerinde olması değildir. Üstelik çocuğun maliyetinin arttışının tartışıldığ1 günümüz koşullarında yalnızca Türkiye'de değil dünya genelinde nüfusunun ağırlıklı çoğunluğunu oluşturan yoksul kesimlerin çocuklarına ayırdıkları payın artmadığını hatırlamalıyız. Aksine çalışma ve sosyal güvenceden yoksun çoğunluk için çocuklar hala gündelik gelirin önemli bir kısmını getiren kaynak durumundadır. Bu açılardan baktığımızda iktisadi rasyonelin kendisinin de tek tip olmadığını, pek çok durumda kısa vadeli iktisadi kazançların uzun vadeli iktisadi kazanç olasılıklarının önüne geçebileceğini göreceğiz.

\section{Teşekkürler:}

Bu makale "Re-placing induced abortion and contraception: a special focus on ethno-cultural differences in the cases of Turkey and selected Central Asian States" başlıklı doktora çalışmama dayanmaktadır. Tez çalışmama ve bu yazının şekillenmesine katkılarından dolayı tez danışmanım Doçent Dr. Banu Akadlı Ergöçmen'e teşekkür ederim. Ayrıca bu yazının taslak halini okuyarak önerileri ile çalışmamı zenginleştiren Güneş Öztürk ve İlknur Yüksel ile Fe Dergisi hakemlerine teşekkür ederim. 
1 Helen King, Hippocrates' Woman. Reading Female Body in Ancient Greece (New York: Routledge, 1998).; John M. Riddle, Contraception and Abortion from the Ancient World to the Renaissance (Cambridge: Harvard University Press, 1994).

${ }^{2}$ Uluslar arası yazınında gebeliği önleyici yöntemler modern (tıbbi) yöntemler, geleneksel (tıbbi olmayan) yöntemler ve folklorik (yöresel) yöntemler olarak üçe ayrılır. Türkiye'de modern yöntemler arasında kadının tüplerinin bağlanması, erkeğin kanallarının bağlanması, hap, rahim içi araç (RİA), enjeksiyon, deri altı implantları, kondom, kadın kondomu, diyafram ve acil korunma hapı; geleneksel yöntemler arasında geri çekme,takvim yöntemi ve emzirme kullanılmakta ayrıca vajinal duj ve bitkilerin kullanılması gibe yöresel yöntemlere rastlanılmaktadır. Hacettepe Üniversitesi Nüfus Etütleri Enstitüsü (HÜNEE), Türkiye Nüfus ve Sağllk Araştırmasl, 2008, (Ankara, Hacettepe Üniversitesi Hastaneleri Basımevi, 2009), 75.

${ }^{3}$ Hacettepe Üniversitesi Nüfus Etütleri Enstitüsü (HÜNEE), Türkiye Nüfus ve Sağlık Araştırması, 2008, 79. ${ }^{4}$ Hacettepe Üniversitesi Nüfus Etütleri Enstitüsü (HÜNEE), Türkiye Nüfus ve Sağllk Araştırması, 2008, 79 ve 85.

5 John Bongaarts ve Charles F. Westoff, "The Potential Role of Contraception in Reducing Abortion" Studies in Family Planning 31, no. 3 (2000): 193-202; Stanley K. Henshaw, Susheela Singh ve Taylor Haas. "Recent trend in abortion rates worldwide", International Family Planning Perspective 25, no. 1 (1999): 44-48; Cicely Marston ve John Cleland, The Effects of Contraception on Obstetric Outcomes (Geneva: World Health Organization, 2004); Pinar Senlet, S. L. Curtis, J. Mathis ve H. Raggers, "The Role of Changes in Contraceptive Use in the Decline of Induced Abortion in Turkey" Studies in Family Planning 32, no. 1 (2001): 41-52.; Charles F. Westoff, C.F. (2000), The Substitution of Contraception for Abortion in Kazakhstan in the 1990s. DHS Analytical Studies No.1. Calverton, Maryland: ORC Macro.; Charles F. Westoff, J. M. Sullivan, H. A. Newby ve A.R. Themme, ContraceptionAbortion Connections in Armenia. DHS Analytical Studies No.6. (Calverton, Maryland: ORC Macro, 2002); Charles F. Westoff, A. Sharmanov ve J. Sullivan, Replacement of Abortion by Contraception in Three Central Asian Republics, (Calverton, MD: The Policy Project and Macro International, 1998)

${ }^{6}$ John Cleland ve Christopher Wilson, "Demand Theories of Fertility Transition: an Iconoclastic View" Population Studies 41 (1987): $5-30$.

${ }^{7}$ John Scott, "Rational Choice Theory," Understanding Contemporary Society: Theories of the Present eds. G. Browning, A. Halcli ve F. Webster (London: Sage Publication, 2000).

${ }^{8}$ Cicely Marston ve John Cleland, The Effects of Contraception on Obstetric Outcomes.

${ }^{9}$ Ansley J. Coale, The Demographic Transition Reconsidered. In Proceedings of the International Population Conference (Liége, 1973), 5372.

10 John C. Caldwell, Bruce K Caldwell, Pat Caldwell, Peter F McDonald ve Thomas Schindlmayr, Demographic Transition Theory (Dordrecht, The Netherlands: Springer, 2006), 418.

${ }^{11}$ Warren Thompson, "Population”, American Journal of Sociology 34 (1929): 959-975.

${ }^{12}$ Kingsley Davis, "The world demographic transition", Annals of the American Academy of Political and Social Science 273 (1945): $1-11$.

${ }^{13}$ Frank W. Notestein, "Population: the long view", Food for the World ed. T.W. Schultz (Chicago: Chicago University Press, 1945).

${ }^{14}$ İsmet Koç, Mehmet Ali Eryurt, Tuğba Adalı ve Pelin Çağatay, Türkiye'nin Demografik Dönüşmü: Doğurganlık, Aile Planlamasl, AnneÇocuk Sağllğı ve Beş Yaş Altı Ölümlerdeki Değişimler: 1968-2008 (Ankara: Hacettepe Üniversitesi Hastaneleri Basımevi, 2010).

${ }^{15}$ Ansley J. Coale, The Demographic Transition Reconsidered.

16 John C. Caldwell, "The Globalization of Fertility Behavior" Global Fertility Transition, Population and Development Review, Supplement to Volume 27 (2001): 93-115.

${ }^{17}$ Tom Fricke. "Culture Theory and Demographic Process: Toward a Thicker Demography," Anthropological Demography: Toward a New Synthesis eds. D.I. Kertzer and T. Fricke (Chicago: The University of Chicago Press, 1997), 248-277.; John Cleland ve Christopher Wilson, "Demand Theories of Fertility Transition: an Iconoclastic View"; Eugene A. Hammel. "A Theory of Culture for Demography" Population and Development Review 16, no. 3 (1990): 445-485.

${ }^{18}$ Scott, "Rational Choice Theory,"

19 David Kertzer ve Tom Fricke, T., "Toward an Anthropological Demography" Anthropological Demography. Towards a New Synthesis eds. David Kertzer ve Tom Fricke (Chicago: University of Chicago Press, 1997), 1-35.

${ }^{20}$ Türkiye'de gerçekleştirilen nüfus ve sağlık araştırmalarının önemli bir kısıtlaması yöntem kullanımı, kürtaj deneyimi ve gebelik tarihçesi sorularının yalnızca başından en az bir evlilik geçmiş kadınlara yöneltilmesidir. Ancak evlilikle kastedilen resmi nikahla sınırlı değildir. Dini nikahla ya da nikahsız olarak bir erkekle birlikte yaşayan kadınlar da evli olarak kabul edilmektedir. Tanımın bu şekilde genişletilmesi kapsayıcılığı çok önemli şekilde arttırmakta olsa da bir erkekle birlikte yaşamayan kadınların cinselliğinin göz 
ardı edildiği unutulmamalıdır. Çocuk sahipliğinin yukarıdaki geniş tanıma göre neredeyse tamamen evlilik içerisinde olduğu Türkiye'de bu kabul ve kısıtlama doğurganlık hızı gibi göstergelerde istatistiksel olarak anlamlı hatalara neden olmaz. Ancak bu durum evlilik dışı cinsellik, yöntem kullanımı ve kürtaj gibi konulardaki örüntüleri kavramamıza izin vermez. Araştırmanın genel işleyişine zarar verebileceği için TNSA'da kapsanmayan evli olmayan kadınların cinsel aktivitesi ile ilgili gibi konularda özel olarak tasarlanmış niceliksel ve niteliksel araştırmalara ihtiyaç vardır. Eşcinsel çiftler ve yalnız ebeveynlerin doğurganlık davranışı ve karar verme süreçleri bu yazının konusu olmamakla beraber son derece ilginç ve güç ilişkilerinin tartışılması açısından zemin yaratıcı bir konudur. Bu alanda yapılacak teorik ve ampirik çalışmalar heteroseksüel ilişkideki dinamiklerin çözümlenmesinde de akıl açıcı olacaktır.

${ }^{21}$ Hacettepe Üniversitesi Nüfus Etütleri Enstitüsü (HÜNEE), Türkiye Nüfus ve Sağlık Araştırması, 2008, 68 ve 110.

${ }^{22}$ Michel Foucault, Cinselliğin Tarihi (İstanbul: Ayrıntı Yayınları, 2003).

${ }^{23}$ İlknur Yüksel Alyanak, Filiz Kardam, İsmet Koç ve Banu Ergöçmen, “Gebeliği Önleyici Yöntem Kullanımına Engel Olan Süreçler,” 2002 Niteliksel Araştırma: Gebeliği Önleyici Yöntemler ve İstemli Düşükler (2003 TNSA Hazırlık Çalışması) Hacettepe Üniversitesi Nüfus Etütleri Enstitüsü, Sağlık Bakanlığı Ana Çoçuk Sağlığı ve Aile Planlaması Genel Müdürlüğü, Devlet Planlama Teşkilatı ve Avrupa Birliği (Orkide Basımevi: Ankara, 2003), 53-54.

${ }^{24} \mathrm{Bu}$ yaklaşım toplumsal cinsiyet eşitsizliğinin içselleşmiş olduğu pek çok indirgemeci yorumda görülebilir. Örneğin eşinden şiddet görmesine rağmen aile birliğini korumak adına kadını karakolda eşine teslim edebilen bir polis, babanın ensest saldırısını annenin açığa nasıl çıkarmamış olduğuna şaşırabilir. Alanur Çavlin Bozbeyoğlu, Türkiye'de Ensest Sorununu Anlamak (Ankara: Damla Matbaac1lık, 2009).

25 Victor Agadjanian, "Is 'abortion culture' fading in the former Soviet Union? Views about abortion and contraception in Kazakhstan" Studies in Family Planning 33, no. 3 (2002): 239.

${ }^{26}$ Elif Ekin Akşit, “Geç Osmanlı ve Cumhuriyet Dönemlerinde Nüfus Kontrolü Yaklaşımları” Toplum ve Bilim 117 (2010): $179-197$.

${ }^{27} 1926$ tarihli Türk Ceza Kanunu, 06.05.1930 tarih ve 1593 sayılı Umumi Hıfıısıhha Kanunu

${ }^{28} 1426$ sayılı Vilayetler İdaresi Kanunu ve 1580 say1lı Belediye Kanunu

${ }^{29} 1938$ yil ve 3453 sayili yasa

30 Ayşe Durakbaşa, "Cumhuriyet Döneminde Modern Kadın ve Erkek Kimliklerinin Oluşumu: Kemalist Kadın Kimliği ve "Münevver

Erkekler"," 75 Yılda Kadınlar ve Erkekler (ed). A. B. Mirzaoğlu (İstanbul: Tarih Vakfi Yurt Yayınları, 1998), 29-50.

${ }^{31}$ 26/9/2004 tarihinde yürürlüğe giren yeni Türk Ceza Kanunun ilgili maddelerinde yapılan değişiklik ile eşin yazılı izni olmadan kürtaj yapılması suç olmaktan çıkmıştır. Ancak Nüfus Kanunu'nda bir değişikliğe gidilmemiştir. Bu durum uygulamada devlete bağlı sağlık kuruluşlarındaki doktorların ya da bazı hukukçuların Nüfus Kanunu'nu referans göstererek eş izni olmadan kürtaj yapılmasına engel olmalarına neden olmaktadır. TCK için bakınız: http://www.tbmm.gov.tr/kanunlar/k5237.html. Örnek olay için bakınız: http://www.haberturk.com/yasam/haber/626489-kurtajla-bu-bebegialin-yoksa-canima-kiyarim HaberTürk 2 Mayıs 2011.

32 Alan Duben ve Cem Behar, İstanbul Haneleri (İstanbul: İletişim Yayınları, 1998).

${ }^{33}$ Elif Ekin Akşit, “Geç Osmanlı ve Cumhuriyet Dönemlerinde Nüfus Kontrolü Yaklaşımları”; Akile Gürsoy, "Abortion in Turkey: a matter of state, family or individual decision" Social Science and Medicine 42, no. 4 (1996): 536.

34 Dorothy McBride Stetson, (1996), "Feminist Perspective on Abortion and Reproductive Technologies" Abortion Politics Public Policy in Cross-Cultural Perspective Eds. Marianne Githend ve Dorothy McBride Stetson (New York: Routledge, 1996$), 213$.

35 Jeffrey Edmeades, Susan M. Lee-Rife ve Anju Malhotra, "Women and reproductive control: the nexus between abortion and contraceptive use in Madhya Pradesh, India" Studies in Family Planning 41, no. 2 (2010): 76; Amir Erfani ve Kevin McQuillan, "Rates of induced abortion in Iran: the roles of contraceptive use and religiosity" Studies in Family Planning 39, no.2 (2008): 112; Nancy Murray ve diğerleri, "Factors related to induced abortion among young women in Edo State, Nigeria" Studies in Family Planning 37, no. 4 (2006): 253.

36 Elif Ekin Akşit, “Kısırlık: Olanak ve Tahakküm” Fe Dergi 1, no. 2 (2009): 44-54.

${ }^{37}$ Hacettepe Üniversitesi Nüfus Etütleri Enstitüsü (HÜNEE), Türkiye'de Doğurganlık, Üreme Sağlı̆̆ı ve Yaşlllık, 2008 Türkiye Nüfus ve Sağlık Araştırması İleri Analiz Çalı̧̧ması (Ankara: Hacettepe Üniversitesi Hastaneleri Basımevi, 2010); İlknur Yüksel Alyanak, Filiz Kardam, İsmet Koç ve Banu Ergöçmen, "Gebeliği Önleyici Yöntem Kullanımına Engel Olan Süreçler,”.

${ }^{38}$ Erhan Özdemir, İsmet Koç ve Arzu Köseli, "Türkiye'de gebeliği önleyici yöntem kullanımını bırakma, yöntem başarısızlığı ve yöntem değiştirme davranışları," Türkiye 2003 nüfus ve Sağlık araştırması İleri Analiz Raporu, Hacettepe Üniversitesi Nüfus Etütleri Enstitüsü, Sağlık Bakanlığı Ana Çoçuk Sağlığı ve Aile Planlaması Genel Müdürlüğü, Devlet Planlama Teşkilatı ve Avrupa Birliği (Ankara, 2005).

${ }^{39}$ P. Senlet, S. L. Curtis, J. Mathis ve H. Raggers, "The Role of Changes in Contraceptive Use in the Decline of Induced Abortion in Turkey".

40ïlknur Yüksel Alyanak, Filiz Kardam, İsmet Koç ve Banu Ergöçmen, “Gebeliği Önleyici Yöntem Kullanımına Engel Olan Süreçler,”, 42.

41 John Bongaarts ve Charles F. Westoff, "The Potential Role of Contraception in Reducing Abortion”.

${ }^{42}$ Hacettepe Üniversitesi Nüfus Etütleri Enstitüsü (HÜNEE), Türkiye’de Doğurganlık, Üreme Sağllğı ve Yaşlıllk, 2008 Türkiye Nüfus ve Sağlık Araştırması İleri Analiz Çalışması, 59.

${ }^{43}$ Kürtajın algılanışı ile ilgili ayrıntılı bilgi için 65 kadınla yapılan derinlemesi görüşmelere dayalı niteliksel araştırma sonuçlarına bakılabilir: Alanur Çavlin Bozbeyoğlu, Elif Kurtuluş and Sabahat Tezcan, "İstemli Düşüğün Algılanılışı ve Nedenleri," 2002 Niteliksel Araştırma: Gebeliği Önleyici Yöntemler ve İstemli Düşükler (2003 TNSA Hazırlık Çalışması) ed. Hacettepe Üniversitesi Nüfus Etütleri Enstitüsü, Sağlık Bakanlığı Ana Çoçuk Sağlığı ve Aile Planlaması Genel Müdürlüğü, Devlet Planlama Teşkilatı ve Avrupa Birliği (Ankara, 2003), 57-79. 
44 Hacettepe Üniversitesi Nüfus Etütleri Enstitüsü (HÜNEE), Türkiye Nüfus ve Sağllk Araştırması, 2003 (Ankara, Hacettepe Üniversitesi Hastaneleri Basımevi, 2004), 87; Alanur Çavlin Bozbeyoğlu, Re-placing induced abortion and contraception: a special focus on ethno-cultural differences in the cases of Turkey and selected Central Asian States (Ankara: Hacettepe Üniversitesi Nüfus Etütleri Enstitüsü, Yayınlanmamış doktora tezi. 2007), 111.

${ }^{45}$ Victor Agadjanian ve Z. Qian, "Ethnocultural identity and induced abortion in Kazakhstan" Studies in Family Planning 28, no. 4 (1997): 317-329; Alanur Çavlin Bozbeyoğlu, Re-placing induced abortion and contraception: a special focus on ethno-cultural differences in the cases of Turkey and selected Central Asian States.

${ }^{46}$ Akşit, "Geç Osmanlı ve Cumhuriyet Dönemlerinde Nüfus Kontrolü Yaklaşımları"

${ }^{47}$ Thomas R. Malthus, First Essay on Population (Ann Arbor:Reprints of University of Michigan Press, 1958 first published in 1798).

${ }^{48}$ Michel Foucault, Cinselliğin Tarihi.

${ }^{49}$ Karl Marx ve Friedrich Engels, Komünist Manifesto ve Komünizmin Ilkeleri (Ankara: Sol Yayınlar1, 2005).

${ }^{50}$ Friedrich Engels, Ailenin, Özel Mülkiyetin ve Devletin Temeli (Ankara: Sol Yayınları, 1979).

\section{Kaynakça}

Agadjanian, Victor. "Is 'abortion culture' fading in the former Soviet Union? Views about abortion and contraception in Kazakhstan" Studies in Family Planning 33, no. 3 (2002): 237-248.

Agadjanian, Victor ve Z. Qian. "Ethnocultural identity and induced abortion in Kazakhstan" Studies in Family Planning 28, no. 4 (1997): 317-329.

Akadlı Ergöçmen, Banu ve Alanur Çavlin Bozbeyoğlu. “An Alternative Approach to Measure Unmet Need for Family Planning in Turkey” Nüfusbilim Dergisi 27 (2005): 3-17.

Akşit, Elif Ekin. "Geç Osmanlı ve Cumhuriyet Dönemlerinde Nüfus Kontrolü Yaklaşımları” Toplum ve Bilim 117 (2010): 179-197.

Akşit, Elif Ekin. “Kısırlık: Olanak ve Tahakküm” Fe Dergi 1, no. 2 (2009): 44-54.

Bongaarts, John ve Charles F. Westoff. "The Potential Role of Contraception in Reducing Abortion” Studies in Family Planning 31, no. 3 (2000): 193-202.

Caldwell, John C., Bruce K Caldwell, Pat Caldwell, Peter F McDonald ve Thomas Schindlmayr. Demographic Transition Theory (Dordrecht, The Netherlands: Springer, 2006).

Caldwell, John C. "The Globalization of Fertility Behavior" Global Fertility Transition, Population and Development Review, Supplement to Volume 27 (2001): 93-115.

Cleland, John ve Christopher Wilson. "Demand Theories of Fertility Transition: an Iconoclastic View" Population Studies 41 (1987): 5-30.

Coale, Ansley J. The Demographic Transition Reconsidered. In Proceedings of the International Population Conference (Liége, 1973), 53-72.

Çavlin Bozbeyoğlu, Alanur. Türkiye'de Ensest Sorununu Anlamak (Ankara: Damla Matbaac1lık, 2009).

Çavlin Bozbeyoğlu, Alanur. Re-placing induced abortion and contraception: a special focus on ethno-cultural differences in the cases of Turkey and selected Central Asian States (Ankara: Hacettepe Üniversitesi Nüfus Etütleri Enstitüsü, Yayınlanmamış doktora tezi. 2007).

Çavlin Bozbeyoğlu, Alanur Elif Kurtuluş and Sabahat Tezcan. "İstemli Düşügün Algıllanılışı ve Nedenleri,” 2002 Niteliksel Araştırma: Gebeliği Önleyici Yöntemler ve İstemli Düşükler (2003 TNSA Hazırlık Çalışması) ed. Hacettepe Üniversitesi Nüfus Etütleri Enstitüsü, Sağlık Bakanlığı Ana Çoçuk Sağlığı ve Aile Planlaması Genel Müdürlüğü, Devlet Planlama Teşkilatı ve Avrupa Birliği (Ankara, 2003),57-79.

Davis, Kingsley. "The world demographic transition", Annals of the American Academy of Political and Social Science 273 (1945): 1-11.

Duben, Alan ve Cem Behar, İstanbul Haneleri (İstanbul: İletişim Yayınları, 1998).

Durakbaşa, Ayşe. "Cumhuriyet Döneminde Modern Kadın ve Erkek Kimliklerinin Oluşumu: Kemalist Kadın Kimliği ve "Münevver Erkekler"," 75 Yllda Kadınlar ve Erkekler (ed). A. B. Mirzaoğlu (İstanbul: Tarih Vakfi Yurt Yayınları, 1998), 2950 .

Edmeades, Jeffrey, Susan M. Lee-Rife ve Anju Malhotra. "Women and Reproductive Control: the Nexus between Abortion 
and Contraceptive Use in Madhya Pradesh, India” Studies in Family Planning 41, no. 2 (2010): 75-88.

Engels, Friedrich. Ailenin, Özel Mülkiyetin ve Devletin Temeli (Ankara: Sol Yayınları, 1979).

Erfani, Amir ve Kevin McQuillan. "Rates of induced abortion in Iran: the roles of contraceptive use and religiosity" Studies in Family Planning 39, no.2 (2008): 111-122.

Fricke, Tom. "Culture Theory and Demographic Process: Toward a Thicker Demography," Anthropological Demography: Toward a New Synthesis eds. D.I. Kertzer and T. Fricke (Chicago: The University of Chicago Press, 1997), 248-277.

Foucault, Michel. Cinselliğin Tarihi (İstanbul: Ayrıntı Yayınları, 2003).

Stetson, Dorothy McBride (1996), "Feminist Perspective on Abortion and Reproductive Technologies" Abortion Politics Public Policy in Cross-Cultural Perspective Eds. Marianne Githend ve Dorothy McBride Stetson (New York: Routledge, 1996).

Gürsoy, Akile. "Abortion in Turkey: a matter of state, family or individual decision” Social Science and Medicine 42, no. 4 (1996): 531-542.

Hacettepe Üniversitesi Nüfus Etütleri Enstitüsü (HÜNEE). Türkiye'de Doğurganlık, Üreme Sağlı̆̆ı ve Yaşlllık, 2008 Türkiye Nüfus ve Să̆lık Araş̧ırması İleri Analiz Çalışması (Ankara: Hacettepe Üniversitesi Hastaneleri Basımevi, 2010).

Hacettepe Üniversitesi Nüfus Etütleri Enstitüsü. Türkiye Nüfus ve Sağlık Araştırmasl, 2008, (Ankara, Hacettepe Üniversitesi Hastaneleri Basimevi, 2009).

Hacettepe Üniversitesi Nüfus Etütleri Enstitüsü. Türkiye Nüfus ve Sağllk Araştırması, 2003 (Ankara, Hacettepe Üniversitesi Hastaneleri Basımevi, 2004).

Hammel, Eugene A. "A Theory of Culture for Demography” Population and Development Review 16, no. 3 (1990): 445485.

Heath, Anthony. Rational Choice and Social Exchange (Cambridge: Cambridge University Press, 1976).

Kertzer, David ve Tom Fricke, T. (1997. “Toward an Anthropological Demography” Anthropological Demography. Towards a New Synthesis eds. David Kertzer ve Tom Fricke (Chicago: University of Chicago Press), 1-35.

King, Helen. Hippocrates' Woman. Reading Female Body in Ancient Greece (New York: Routledge, 1998).

Koç, İsmet, Mehmet Ali Eryurt, Tuğba Adalı ve Pelin Çağatay. Türkiye’nin Demografik Dönüşmü: Doğurganlık, Aile Planlaması, Anne-Çocuk Să̆llğı ve Beş Yaş Altı Ölümlerdeki Değişimler: 1968-2008 (Ankara: Hacettepe Üniversitesi Hastaneleri Basımevi, 2010).

Malthus,Thomas R. First Essay on Population (Ann Arbor:Reprints of University of Michigan Press, 1958 first published in 1798).

Marston, Cicely ve John Cleland. The Effects of Contraception on Obstetric Outcomes (Geneva: World Health Organization, 2004).

Marx, Karl ve Friedrich Engels, Komünist Manifesto ve Komünizmin Ilkeleri (Ankara: Sol Yayınları, 2005).

Murray, Nancy ve diğerleri. "Factors related to induced abortion among young women in Edo State, Nigeria" Studies in Family Planning 37, no. 4 (2006): 251-268.

Notestein, Frank W. "Population: the long view", Food for the World ed. T.W. Schultz (Chicago: Chicago University Press, 1945).

Özdemir, Erhan İsmet Koç ve Arzu Köseli. "Türkiye'de gebeliği önleyici yöntem kullanımını bırakma, yöntem başarısızlığı ve yöntem değiştirme davranışları," Türkiye 2003 nüfus ve Sağllk araştırması İleri Analiz Raporu, Hacettepe Üniversitesi Nüfus Etütleri Enstitüsü, Sağlık Bakanlığı Ana Çoçuk Sağlığı ve Aile Planlaması Genel Müdürlüğü, Devlet Planlama Teşkilatı ve Avrupa Birliği (Ankara, 2005).

Senlet, S. L. Curtis, J. Mathis ve H. Raggers, "The Role of Changes in Contraceptive Use in the Decline of Induced Abortion in Turkey" Studies in Family Planning 32, no. 1 (2001): 41-52.

Riddle, John M. Contraception and Abortion from the Ancient World to the Renaissance (Cambridge: Harvard University Press, 1994).

Scott, John. "Rational Choice Theory," Understanding Contemporary Society: Theories of the Present eds. G. Browning, A. Halcli ve F. Webster (London: Sage Publication, 2000).

Thompson, Warren. "Population”, American Journal of Sociology 34 (1929): 959-975. 
Westoff, Charles F. (2000), The Substitution of Contraception for Abortion in Kazakhstan in the 1990s. DHS Analytical Studies No.1. Calverton, Maryland: ORC Macro.

Westoff, Charles F., J. M. Sullivan, H. A. Newby ve A.R. Themme, Contraception-Abortion Connections in Armenia. DHS Analytical Studies No.6. (Calverton, Maryland: ORC Macro, 2002).

Westoff, Charles F., A. Sharmanov ve J. Sullivan, Replacement of Abortion by Contraception in Three Central Asian Republics, (Calverton, MD: The Policy Project and Macro International, 1998).

Yüksel Alyanak, İlknur, Filiz Kardam, İsmet Koç ve Banu Ergöçmen. "Gebeliği Önleyici Yöntem Kullanımına Engel Olan Süreçler,” 2002 Niteliksel Araştırma: Gebeliği Önleyici Yöntemler ve İstemli Düşükler (2003 TNSA Hazırlık Çalışması) Hacettepe Üniversitesi Nüfus Etütleri Enstitüsü, Sağlık Bakanlığı Ana Çoçuk Sağlığı ve Aile Planlaması Genel Müdürlügü̆, Devlet Planlama Teşkilatı ve Avrupa Birliği (Orkide Basımevi: Ankara, 2003), 31-56. 